\title{
PERCEPTUAL KNOWLEDGE OF NONACTUAL POSSIBILITIES
}

\author{
Margot Strohminger \\ University of Antwerp
}

It is widely assumed that sense perception cannot deliver knowledge of nonactual (metaphysical $^{1}$ ) possibilities. We are not supposed to be able to know that a proposition $p$ is necessary or that $p$ is possible (if $p$ is false) by sense perception. This paper aims to establish that the role of sense perception is not so limited. It argues that we can know lots of modal facts by perception. While the most straightforward examples concern possibility and contingency, others concern necessity and impossibility. The possibility of a perceptual route to some modal knowledge is not as radical as it may at first sound. On the contrary, acknowledging it has benefits.

\section{Perception in the epistemology of modality}

Sense perception is typically supposed to play an extremely limited role in the epistemology of modality. This assumption follows from a widely accepted thesis about the extent of a posteriori knowledge. According to it, experience cannot deliver knowledge of how the world must be or of how the world might have been but is not-or what I will call 'knowledge of nonactual possibilities'. Endorsements of the thesis that experience cannot deliver knowledge of nonactual possibilities are not hard to find. Salmon writes that "empirical investigation conducted in the actual world directly yields information only about the actual world, not about other possible worlds" (2005, 254), and Chalmers remarks that "a posteriori information only tells us about our world" (1996, 137). Indeed, the thesis sometimes serves as the starting point for discussions about the epistemology of modality. For example, Hale writes:

Kant famously remarked that we may learn from experience what is the case, but not what must be. He might have added that experience-roughly, sense-perception and introspection, together with what we can infer from their deliverances-leaves us almost equally in the dark about what might be. Not quite, of course, since wherever experience teaches us that $p$, we may safely infer, ab esse ad posse, that it is possible that $p$. But the interesting question concerns knowledge of unrealized possibilities (and of possibilities not known to be realized). It is precisely because possibilities may go unrealized that experience cannot teach us what must be so-for if it is true, but merely contingently so, that $p$, then it is possible that not- $p$, but this possibility goes unrealized. Experience may inform us that $p$, but to know that it is not just true,

\footnotetext{
${ }^{1}$ Unless context indicates otherwise, I will use 'modal(ity)', 'possible' ('possibility'), and so on to talk about metaphysical modality.
} 
but necessary that $p$, we need to know that there is no (unrealized) possibility that not-p. $(2013,252)^{2}$

Defenses of alternative sources of modal knowledge often presuppose the assumption. This is striking, since knowledge of nonactual possibilities could be perceptual in some cases, and non-perceptual in others. One example is Yablo's (1993) defense of the principle that if someone $S$ conceives that $p$, then $S$ is thereby prima facie justified in believing that it is possible that $p$. In setting up his view, he assumes that, together with inference and testimony, conceiving constitutes the only basis for arriving at beliefs of the form 'It is possible that $p^{\prime}$, which does not rely on $p$. Yablo writes of conceivability: "if there is a seriously alternative basis for possibility theses, philosophers have not discovered it" $(1993,2){ }^{3}$ Proponents of the view that (rational) intuitions are a source of modal knowledge provide another example. On their view, intuitions are experiences that are 'intellectual' rather than sensory in character, which, like the latter, can justify a range of beliefs. ${ }^{4}$ Part of the reason that intuitions are posited is that sensory experiences are supposed to be very limited in the kind of contents they can justify. In particular, modal contents seem to be excluded. Just as sensory experiences deliver information about the actual world, the picture seems to be, intuitions deliver information about other possible worlds. When combined with the standard assumption that the only concrete possible world is the actual world, this falls out of the view that

...while sensory perceptions are experiences that purport to, and sometimes do, reveal how matters stand in concrete reality by making us sensorily aware of that reality, intuitions are experiences that purport to, and sometimes do, reveal how matters stand in abstract reality by making us intuitively aware of that reality. (Chudnoff 2013, 1)

The above remarks suggest the view that perception cannot provide us with knowledge about how the world must be or about how the world might have been but is not. We can summarize the view in the following slogan: perceptual knowledge of nonactual possibilities is impossible. According to this view, we cannot know by perception that some proposition $p$ is necessary or that some false proposition $p$ is possible. The view also rules out some perceptual knowledge of claims that do not involve metaphysical-modal operators at all. For example, perceptual knowledge of unexercised abilities or counterfactual conditionals with

\footnotetext{
2 See Hale 2003, 1 for his original statement of this point.

${ }^{3}$ Of course there is sometimes an alternative method for determining $p^{\prime}$ s possibility when $p$ is true, as Yablo $(1993,1, \mathrm{n} .1)$ acknowledges. If one knows that $p$, then one can infer $\diamond p$ from $p$ by ab esse ad posse. Thus, I take it that what Yablo means by a 'serious' alternative method is one that applies to possibility claims $\diamond p$, when $p$ is not known-for example, because $p$ is false.

4 This view has found many defenders in recent years including, most recently, Chudnoff (2013) and Bengson (2015).
} 
false antecedents is also ruled out since they concern how the world could have been but is not. ${ }^{5}$

Is the role of perception in the epistemology of modality really so limited? This question is rarely raised, let alone answered in the negative. ${ }^{6}$ The aim of this paper is to defend the negative answer. Instead, some of our knowledge of nonactual possibilities can be, and very often is, perceptual. To do this, I first clarify what it takes for an item of knowledge to be perceptual (Section 2). I then argue that some of our knowledge of nonactual possibilities is perceptual (Section 3). Finally, I argue that this conclusion is less radical than it may at first sound, and even has positive consequences (Section 4).

\section{Knowledge by sense perception}

Knowledge by sense perception is knowledge obtained in a certain way. For convenience, I will call it 'perceptual knowledge'. The conception of perceptual knowledge I will rely on is more demanding than Dretske's $(1969,2010)$, but still importantly related. Perceptual knowledge in the sense of interest is, like Dretske's, "psychologically immediate" and directed at "facts we describe ourselves as learning, as coming to know, by perceptual means" (Dretske 2010, 582). Or, as Millar puts it, it "arises immediately from current perception, that is, without inference from prior assumptions" (2000, 74).

Consider visual knowledge, as opposed to knowledge obtained by other sense modalities, for the time being. There seems to be a sense of 'see that', which can be paraphrased as 'know by the sense of vision' ${ }^{7}$ Suppose that I tell you that I saw that the suspect was wearing a black hat. In saying this, I am not only conveying that I know or came to know that the suspect was wearing a black hat. Rather, I convey that I came to know it in a certain way, namely by vision. Gisborne's (2010, ch. 4) linguistic treatment of propositional 'see' vindicates this contention. According to Gisborne, propositional 'see' has three senses. While one sense of 'see' can be paraphrased as 'know by the sense of vision', 'see' has two other senses, which have nothing in particular to do with vision. Specifically, there are senses of 'see' that can

\footnotetext{
${ }^{5}$ It is not clear whether the view can be stated much more precisely without encountering obvious counterexamples. Consider the claim that one cannot know any proposition that logically entails anything of the form $\square p$ or of the form $\diamond p$ (unless $p$ is true) by perception. That cannot be what is intended since any statement entails the necessity of a truth-functional tautology (e.g. $p$ entails $\square(q \vee \neg q)$ ); it would then follow that any item of perceptual knowledge is a counterexample to the view. Thanks to Juhani Yli-Vakkuri for pointing out this difficulty.

${ }^{6}$ Dever (2007, 1-2), Hill (2014, 286) and Williamson (manuscript) are notable exceptions, although they only discuss the issue tangentially.

7 This view can be traced back at least to Dretske 1969.
} 
be paraphrased as 'know' and 'realize'. ${ }^{8}$ Someone might see that a conjecture is true, or that two people don't get along, even when the knowledge being reported on is not visual. Unlike the latter general epistemic senses of 'see', the first, visualepistemic sense can be modified by gaze-related directional prepositions like 'through the window' (Gisborne 2010, 145-46).

There is a problem with thinking that the characterization provided so far captures a very interesting epistemic category, at least for my purposes. Consider the following:

(1) I saw that it was 18 degrees Celsius.

(2) I saw that there was a school shooting.

There are contexts in which (1) and (2) can be modified by gaze-related directional prepositions. If I came to know the temperature by consulting the thermometer outside my window, then I saw through the window that it was 18 degrees. If I came to know about the most recent school shooting by reading a headline, then I saw, in the paper (or on the computer screen), that there was a school shooting. Once this is recognized, it becomes clear that similar remarks apply to a range of contents, including modal contents. Suppose that I read in a philosophy journal the sentence, 'It is necessary that Hesperus is Phosphorus'. Let's assume that I can know the claim by reading this sentence. Then, intuitively, there is a sense in which I knew it by vision. I saw, in the journal, that it is necessary that Hesperus is Phosphorus. ${ }^{9}$ On this conception, perceptual knowledge of nonactual possibilities is easy to come by. Cases like these show that thisconception is too permissive to be of much interest for my purposes.

In what follows, I will assume that perceptual knowledge does not include cases like the knowledge that I acquired in the examples just given. The latter cases are all indirect in that they involve my seeing something other than what the claim known is about. I learn something about the temperature (campus events, Hesperus...) by seeing something else (a thermometer, words on a page...). Instead, we are looking for a category of perceptual knowledge that is suitably direct. To get at this category of knowledge, consider the effect of modifying perceptual verbs like 'see' with the modal auxiliary 'can'. Williamson $(2000,37)$ notices a contrast between pairs like (2) and (3):

(2) I saw that there was a school shooting.

(3) I could see that there was a school shooting.

\footnotetext{
${ }^{8}$ Gisborne's discussion uses 'understand', but I assume that 'know' is interchangeable with 'understand' in this propositional usage. See Sliwa 2015 for defense.

${ }^{9}$ Many of my examples of the necessary a posteriori, such as this one, are drawn from or inspired by Kripke 1980.
} 
Unlike (2), (3) seems like it can be true only if I am an eyewitness of the event. More generally, there is a contrast between ' $S$ saw that $p$ ' and ' $S$ could see that $p$ ', even when 'saw' has its visual-epistemic sense. As a result, we cannot truly say, in describing the context in which I read the journal announcing that 'It is necessary that Hesperus is Phosphorus' as one in which I could see that it was necessary that Hesperus was Phosphorus. Expressions like 'can feel' and 'can hear' also serve to pick out other varieties of perceptual knowledge that are similarly directspecifically, direct tactile and auditory knowledge (Williamson 2000, 36-37). So, in what follows, I will assume that if someone can see (or hear or feel...) that $p$, then she has perceptual knowledge that $p$. A fuller account of perceptual knowledge that respects this assumption may be possible, but it will not be needed for my purposes. ${ }^{10}$

\section{Perceptual knowledge of nonactual possibilities}

We are now in a position to ask whether we can have perceptual knowledge of nonactual possibilities. Consider the following claims:

(4) I can reach the mug.

(5) I can climb the tree.

(6) It is metaphysically possible that I climb the tree.

(7) The house could have been yellow.

(8) Necessarily, this is different from that (said of two objects in my visual field).

I will argue that if we can know (4)-(8) at all, then we can know (4)-(8) perceptually. I take it be plausible that we can know some of (4)-(8), and I will not be concerned with converting a modal skeptic who is already convinced otherwise. ${ }^{11}$ Rather, my focus is on addressing someone who is happy to allow for some knowledge of nonactual possibilities, but maintains that it can never be perceptual.

We can start by considering judgments like (4) and (5), which concern the possibility of actions with respect to our immediate surroundings. These judgments are often made quickly and effortlessly. I look at a mug, and judge that I can reach it. Or I look at a tree, and judge that I can climb it. Or someone throws a ball at me and, before catching it, I judge that I can catch it. No conscious reasoning intervenes between my seeing the mug, tree or ball, and making the modal judgment about it. Even when they are formed in this way, these beliefs have a good claim to being

10 Here I have in mind especially Millar's (e.g. 2000, 2010) account of what he calls 'perceptual knowledge' or 'basic perceptual knowledge' in terms of (basic) perceptualrecognitional abilities.

${ }_{11}$ Although I will argue that one consideration used to motivate modal skepticism does not apply to claims (4)-(6) in Sect. 4. 
classified as knowledge. We are very reliable at making some such judgments, for example.

We seem to be able to describe these beliefs in the ways typical of perceptual knowledge. We can report on the beliefs using propositional 'see': 'I see that I can reach the mug', 'I see that I can climb the tree', and 'I see that I can catch the ball'. These reports seem true. Moreover, we seem to be able to modify these 'see'-reports with gaze-related directional prepositions. For example, suppose that when I come to know that I can climb a certain tree upon seeing it, I am inside, looking at the tree through a window. Hence, I saw through the window that I could climb the tree. I see, through my glasses, that I can reach the mug on my desk or that I can catch the ball being thrown at me. Most importantly, typically I also can see that I can reach the mug. I am looking at the mug, and judging that it is reachable for me. My knowledge is not indirect as when I look at a thermometer and judge the temperature, or read a headline and judge something about current events.

Knowledge about our abilities when these abilities are not being exercised qualifies as knowledge of nonactual possibilities. Claims which attribute abilities to someone or something entail metaphysical-possibility claims. For example, a claim of the form, 'S can $\phi$ ' ('I can reach the mug'), entails the possibility claim, 'It is metaphysically possible that $S \phi^{\prime}$ ('It is metaphysically possible that I reach the mug'). ${ }^{12}$ Ability claims are unlike claims involving epistemic possibility in this respect. 'It is epistemically possible that $p$ ' does not entail 'It is metaphysically possible that $p^{\prime}$. Mathematical conjectures are sometimes metaphysically impossible yet epistemically possible. When an ability claim concerns an ability that is not currently being exercised, it entails a nonactual possibility claim.

Thus, some of our knowledge of nonactual possibilities is perceptual. Knowledge of unexercised abilities is not special in this regard either. Our perceptual knowledge of nonactual possibilities extends more broadly. Specifically, we can know by perception contents directly involving metaphysical-modal operators including the necessity operator. To appreciate this, it will help to start by reflecting on how knowledge that can be obtained by inference can sometimes also be obtained by perception.

Consider possible routes to knowing the species membership of a bird I am looking at. One way I can figure out that the bird is an oriole, say, is by inferring it from some further claims (to simplify, that the bird has plumage with certain markings, and that the bird is an oriole if it has those markings). But this inference

12 This is a consequence of a standard treatment of ability claims, which analyzes them as claims of the form, 'It is possible that $p^{\prime}$, where the flavor of possibility is a restriction on metaphysical possibility (Lewis 1976, Kratzer 1977). The entailment seems plausible even in the absence of this standard treatment, though (for an alternative that preserves the entailment, see Vetter 2015). See Spencer forthcoming for an argument against the entailment. 
isn't necessary, at least after getting into a routine of identifying orioles. I can use perception to figure out the claim instead. Again, this is reflected in the way we speak: I can see that there is an oriole (and if the bird is in front of my window, I can see that through my window). Sometimes, as in this example, a certain level of expertise is required to reach the knowledge perceptually.

This familiar point has applications to certain of our modal beliefs, too. A wide range of modal claims can, at least after suitable training, be known by sense perception in addition to inference. Consider the following arguments:

(A1) I can reach the mug.

If I can reach the mug, then it is metaphysically possible that I reach the mug.

Thus, It is metaphysically possible that I reach the mug.

(A2) The house is black.

The house could have been some color other than its actual color.

Thus, Possibly, the house is not black.

Let's assume that we can know the conclusion by inferring it from the two premises in each case. If we know the conclusion at all, we can know it by perception. We routinely form beliefs in claims like the first premise here. We can also get into the habit of forming the belief in the conclusion whenever we see the same scene that prompts belief in the first premise. I can see that the house is black. I can also see that it could have been yellow.

The same strategy can be mimicked for lots of our knowledge of nonactual possibilities normally arrived at by chains of reasoning, where one premise is known by perception. Consider how the Principle of the Necessity of Distinctness allows one to conclude that any two distinct things are necessarily distinct by reasoning along the following lines:

(A3) This $\neq$ that.

For any $x, y$, if $x \neq y$, then necessarily, $x \neq y$.

Thus, Necessarily, this $\neq$ that.

I can sometimes see that two objects in my visual field are distinct. I can see that the glass is not the mug. If I accept the Principle of the Necessity of Distinctness, I might reason to the conclusion that it is necessary that the glass is not the mug. This reasoning can become unconscious or automatic by habit. Whether the reasoning is 
conscious or unconscious, it can yield knowledge. ${ }^{13}$ Eventually I can just see that it is necessary that the glass is not the mug. Similarly, I might see that a certain table is made of wood and then reason to the conclusion that it is necessarily made of wood. While normally I explicitly rely on some principle that implies that the table is necessarily made of wood if it is made of wood, this is optional. I might implicitly rely on a background belief in the principle instead. If one knows that the table is necessarily made of wood by explicit reasoning, then the same should be said when the reasoning is implicit but otherwise identical. In that case, one can see that the table is necessarily made of wood. ${ }^{14}$

So far I have suggested several examples of visual knowledge of nonactual possibilities. While the focus has been on vision, other sense modalities also seem to be capable of providing knowledge of nonactual possibilities. Someone might come to know by the sense of touch that they can climb a certain tree. They feel the surface of the tree, and come to know that they can climb it. They can feel that they can climb the tree. Different senses can also jointly contribute to one's modal knowledge. Someone might judge that they can climb the tree only after both inspecting it with their eyes and their hands. Perceptual knowledge of nonactual possibilities is possible and, especially where unexercised abilities to perform certain actions are concerned, is sometimes even the typical form our knowledge takes. It should be clear too how the foregoing remarks provide a recipe for generating further counterexamples to the generalization that knowledge of nonactual possibilities cannot be perceptual. ${ }^{15}$

\section{Consequences of the view}

So far I have argued that some claims about nonactual possibilities can be, and often are, known by perception. I am not suggesting that perception has the ability to explain all of our knowledge of nonactual possibilities, even when supplemented with inference and testimony. There are many instances of knowledge of nonactual

${ }^{13}$ Epistemologists disagree over whether the person needs to know the principle. For some, it will be enough that the person believes the principle. My point is only that if we can know the necessity claim by conscious reasoning, then we can also know it by the sense of vision, where this includes unconscious reasoning. I certainly do not require that these background beliefs be perceptually knowable; as Dretske notes, they do not seem to be $(2010,584)$.

${ }^{14}$ A similar point can be made about knowledge that it is essential to the table that it is made of wood, even if this claim is treated as different from the claim that it is necessary that the table is made of wood, as in Fine 1994.

15 For example, the same strategy can be deployed to show that some knowledge of counterfactual conditionals with false antecedents is perceptual. Just as I can see that I can reach the mug, I can also see that I would touch the mug were I to extend my arm along a certain path. This role for perception in the epistemology of counterfactuals is more important than the one in Williamson's account, which already allows that "[p]erceptual input is crucial to the evaluation of [certain] counterfactuals" $(2007,148)$. 
possibilities that cannot be based on sense perception. Thought experiments seem to be capable of yielding modal knowledge. However they do so, it is clear that the knowledge is not perceptual. Some humdrum knowledge of our abilities cannot be perceptual either. A mathematician might know that she can prove a certain conjecture, even though she has not yet done so. It seems clear that the mathematician's knowledge cannot be perceptual. As a result, the epistemologist of modality will need to invoke something else to avoid skepticism about some cases of modal knowledge. Moreover, many contents that are known perceptually can be known by other means. Williamson (2016) suggests that one way we can assess whether we can do something is by imagining trying. Plausibly there is some overlap with some of the examples discussed here. I might imagine myself trying to climb the tree in order to assess whether I can climb it.

Nevertheless, the perceptual account described in the previous section promises to explain a lot of the modal knowledge that we ordinarily take ourselves to possess. In many cases, the perceptual route is much more psychologically realistic than alternatives that have been described in the literature. Consider how existing accounts handle someone's knowledge that it is metaphysically possible that they reach the mug in front of them. They will appeal to someone's having had an intuition or performed a certain imagining or a certain inference. ${ }^{16}$ Sometimes we simply do not seem to be exploiting any of these routes. Rather, we know the claim in question by perception, or by inferring it from an ability claim, which is itself known by perception. Our knowledge of metaphysical possibility is often obtained by a route that also results in knowledge of abilities. The perceptual account I offered shows how this can happen. ${ }^{17}$

The account also can be used to provide a new refutation of some forms of modal skepticism. Although the previous section focused specifically on arguing that if certain modal claims are knowable at all, they are knowable perceptually, a strong case for their knowability can also be made. In particular, the evolutionary considerations sometimes employed by modal skeptics can be used to block skepticism about unexercised abilities in general. ${ }^{18}$ Nozick (2001) doubts the possibility of knowing any proposition to be metaphysically necessary by assuming that there would be no selective pressure to make judgments of necessity accurately. Whether this strategy is in the end successful or not, it cannot be extended to knowledge of unexercised abilities. We form beliefs about our abilities in relation to our immediate environment all of the time. An ability to make judgments concerning nonactual possibilities relevant to future action accurately is clearly advantageous. If

\footnotetext{
16 See Bealer 2002, Yablo 1993, Williamson 2007, and Roca-Royes forthcoming.

17 An imagination-based account can too if, as Williamson (2016) suggests, we can use certain highly constrained imaginings to evaluate claims about our abilities.

18 The strategy here is broadly similar to Williamson's (2007, ch. 5) and Kroedel's (2012) in response to skepticism about counterfactuals.
} 
we get things wrong, there can be disastrous consequences. Consider someone who, confronted with a ravine, judges that it is easily jumpable for her and acts upon this judgment. Given the selective pressures on the ability to make such modal judgments, we should expect humans to get better at making them over time, and in turn for these beliefs to at least sometimes constitute knowledge. Moreover, given the entailment from ability claims to metaphysical-possibility claims, we should also expect these capacities to enable us to obtain knowledge of claims of the latter sort, too.

The account also respects constraints that are in some sense naturalistic. Importantly, it respects Williamson's (2007) 'anti-exceptionalist' constraint. According to anti-exceptionalism, the only cognitive capacities an account of modal knowledge should rely on are "cases of general cognitive capacities used in ordinary life, perhaps trained, developed, and systematically applied in various special ways" (Williamson 2007, 136). The account on offer is very clearly compatible with antiexceptionalism since the only capacities it makes use of are sense perception and (in some cases) inference: these are 'ordinary' if any are. Using the account, we can refute a skeptic who doubts that knowledge of nonactual possibilities is possible.

While Williamson also aims to provide an account that respects antiexceptionalism, my account relies on different assumptions, and thus can be persuasive to those unconvinced of Williamson's. According to Williamson, we can obtain metaphysical-modal knowledge by using the methods conducive to knowledge of certain logically equivalent counterfactual conditionals. In particular, the strategy rests on the claim that 'It is metaphysically necessary that $p^{\prime}$ is logically equivalent to 'If it were the case that $\neg p$, then a contradiction would obtain', or $(\square)$ :

$(\square) \quad \square p \equiv(\neg p>\perp) \cdot{ }^{19}$

In a very minimal counterfactual logic, $(\square)$ entails that counterfactuals with metaphysically impossible antecedents, or '(metaphysical) counterpossibles', are vacuously true. ${ }^{20}$ Many find it intuitive to say that some counterpossibles are false. Those who wish to take these intuitions seriously ${ }^{21}$ cannot avail themselves of Williamson's strategy. ${ }^{22}$ The strategy also requires an epistemology of counterfactual conditionals, which is still poorly understood. Williamson sketches an account in terms of supposing the antecedent of the counterfactual and then developing it in

19 See also Hill 2006, 219-28. For precursors, see the definitions in Stalnaker 1968 and Lewis 1973.

${ }^{20}$ Any logic that validates both $(p>\perp) \rightarrow(p>q)$ and $(\square)$ and is closed under tautological consequence (such as the logics of Stalnaker 1968 and Lewis 1973) also validates $\neg \diamond p \rightarrow(p>$ $r$ ), i.e. the principle that all counterpossibles are true.

${ }^{21}$ See e.g. Nolan 1997 and Dorr 2008.

${ }^{22}$ This limitation is shared by other modal-epistemological accounts that rest on $(\square)$, such as Hill's (2006), Kroedel's (2012) and Yli-Vakkuri's (2013). 
the imagination $(2007,152-53)$. Since then, Williamson (2016) develops his stance as involving the controversial claim that some imaginings can yield knowledge. The perceptual account I supplied does not require any account of counterfactual knowledge in order to succeed. No detour through counterfactuals is needed.

The view that some knowledge of nonactual possibilities is perceptual thus has several attractive consequences. In closing, I would like to emphasize the difference between the view on offer and three others in the vicinity. First, I am not claiming that we can perceive things that could have existed but do not, or events that could have occurred but have not. I have not claimed, for example, that when someone can see that she can reach a certain mug, she is seeing a merely possible situation in which she reaches the mug, or a merely possible mug. In general, what we can objectually see or otherwise perceive does not neatly align what what we can propositionally see or otherwise perceive. Presumably one can sometimes see that there are no tigers in the room. This fact is compatible with the claim that one cannot see absent tigers.

Second, I am not claiming that sensory experiences themselves ever have modal contents. So, for example, I have not claimed that when someone knows by visual perception that she can climb the tree, her visual experience has the content that the tree is climbable for her. Arguably, perceptual knowledge is possible even when the content known is not represented in sensory experience. I have perceptual knowledge that I have hands. After all, I can see that I have hands. One can acknowledge this without saying that the knowledge-conferring experience itself has the content that I have hands.

Finally, I am not claiming that sensory experiences can immediately justify claims that concern nonactual possibilities. If you know something by perception, then you are (at least on standard views) justified in believing it to be true. But it does not follow that you are immediately justifed in believing it to be true. More is needed. For example, on one standard construal, in order for a justified belief to be immediately justified, it cannot "rest on any evidence or justification that you have for believing other propositions" (Pryor 2000, 532).

The view that some knowledge of nonactual possibilities is perceptual is different from the three preceding claims. Perhaps the widespread rejection of the view on offer can in part be explained by its conflation with claims in the vicinity such as these. Nevertheless, epistemologists of modality should not reflexively reject them either. The view that sensory experiences can have modal contents has some degree of plausibility. According to a tradition in perceptual psychology tracing back to Gibson (1979, 1986), we represent modal properties like reachability in visual experience directly. ${ }^{23}$ There also does not seem to be strong reason to deny that sensory experiences can immediately justify some modal claims such as claims about

${ }^{23}$ For more recent defense, see Nanay 2011, 2012 and Siegel 2010, ch. 5 (although in the case of the latter, the focus is on the representation of causation). 
unexercised abilities. ${ }^{24}$ Those experiences that putatively represent modal properties would seem to be plausible candidates for this role.

\section{Conclusion}

We have lots of knowledge about how things must be and of how they could have been but are not. Contrary to a widespread assumption, we can sometimes obtain this kind of knowledge by sense perception. Routes to some knowledge of metaphysical modality include ones even more familiar than those suggested by other anti-exceptionalist accounts such as Williamson's (2007). The defense of perceptual knowledge of nonactual possibilities offered here is compatible with there being other limitations on the role sense experience can play in the acquisition of modal knowledge. Nevertheless, epistemologists of modality should be careful not to unthinkingly assume the existence of these limitations on sense experience either. Perhaps they are no more real than the limitation that has been the focus of this paper. ${ }^{25}$

\section{References}

Bealer, George. 2002. "Modal Epistemology and the Rationalist Renaissance." In Conceivability and Possibility, edited by Tamar Szabó Gendler and John Hawthorne, 71-125. Oxford: Clarendon Press.

Bengson, John. 2015. “The Intellectual Given." Mind 124: 707-60.

Chalmers, David J. 1996. The Conscious Mind. Oxford: Oxford University Press.

Chudnoff, Elijah. 2013. Intuition. Oxford: Oxford University Press.

Dever, Josh. 2007. “Low-Grade Two-Dimensionalism.” Philosophical Books 48: 1-16.

Dorr, Cian. 2008. "There Are No Abstract Objects." In Contemporary Debates in Metaphysics, edited by Ted Sider, John Hawthorne, and Dean W. Zimmerman, 32-63. Oxford: Blackwell.

Dretske, Fred. 1969. Seeing and Knowing. London: Routledge and Kegan Paul.

-2010. "Perceptual Knowledge." In A Companion to Epistemology, edited by Jonathan Dancy, Ernest Sosa and Matthias Steup, 581-86. 2nd ed. Malden, MA: Wiley-Blackwell.

Fine, Kit. 1994. "Essence and Modality." Philosophical Perspectives 8: 1-16.

Gibson, James J. 1979. The Ecological Approach to Visual Perception. Boston: Houghton Mifflin.

-1986. "The Theory of Affordances." Reprinted in Perceiving, Acting, and Knowing, edited by Robert Shaw and John Bransford, 127-43. Hillsdale, NJ: Lawrence Erlbaum.

Gisborne, Nikolas. 2010. The Event Structure of Perception Verbs. Oxford: Oxford University Press.

Hale, Bob. 2003. "Knowledge of Possibility and of Necessity." Proceedings of the Aristotelian Society 103: $1-20$.

-2013. Necessary Beings: An Essay on Ontology, Modality, and the Relations Between Them. Oxford: Oxford University Press.

${ }^{24}$ I hope to address this issue in future work.

25 Thanks to Jessica Brown, Dan Cavedon-Taylor, Dominic Gregory, John Hawthorne, Beau Mount, Bence Nanay, Sonia Roca-Royes, Anand Vaidya, Barbara Vetter, Tim Williamson, Juhani Yli-Vakkuri and audiences at the Universities of Oxford, Antwerp and Stirling for their comments on this paper. 
Hill, Christopher S. 2006. "Modality, Modal Epistemology, and the Metaphysics of Consciousness." In The Architecture of the Imagination, edited by Shaun Nichols, 205-36. Oxford: Oxford University Press.

-2014. "Conceivability and Possibility." In Meaning, Mind, and Knowledge, 273-96. Oxford: Oxford University Press.

Kratzer, Angelika. 1977. "What 'Must' and 'Can' Must and Can Mean." Linguistics and Philosophy 1: 337-55.

Kripke, Saul A. 1980. Naming and Necessity. Oxford: Blackwell.

Kroedel, Thomas. 2012. "Counterfactuals and the Epistemology of Modality." Philosophers' Imprint 12: $1-14$.

Lewis, David K. 1973. Counterfactuals. Oxford: Basil Blackwell.

-1976. “The Paradoxes of Time Travel." American Philosophical Quarterly 13: 145-52.

-1986. On the Plurality of Worlds. Oxford: Blackwell.

Millar, Alan. 2000. "The Scope of Perceptual Knowledge." Philosophy 1: 73-88.

-2010. "Knowledge and Recognition." In The Nature and Value of Knowledge: Three Investigations, by Duncan Pritchard, Alan Millar, and Adrian Haddock, 91-188. Oxford: Oxford University Press.

Nanay, Bence. 2011. “Do We See Apples as Edible?" Pacific Philosophical Quarterly 92: 305-22.

-2012. "Action-Oriented Perception." European Journal of Philosophy 20: 430-46.

Nolan, Daniel. 1997. "Impossible Worlds: A Modest Approach." Notre Dame Journal of Formal Logic 38: 535-73.

Nozick, Robert. 2001. Invariances: The Structure of the Objective World. Cambridge, MA: Harvard University Press.

Pryor, James. 2000. "The Skeptic and the Dogmatist." Noûs 34: 517-49.

Roca-Royes, Sonia. forthcoming. "Similarity and Possibility: An Epistemology of De Re Possibility for Concrete Entities." In Modal Epistemology After Rationalism, edited by Bob Fischer and Felipe Leon. Dordrecht: Synthese Library.

Salmon, Nathan. 2005. Reference and Essence. $2^{\text {nd }}$ ed. Amherst, NY: Prometheus Books.

Siegel, Susanna. 2010. The Contents of Visual Experience. Oxford: Oxford University Press.

Sliwa, Paulina. 2015. "Understanding and Knowing." Proceedings of the Aristotelian Society 115: 57-74.

Spencer, Jack. forthcoming. "Able to Do the Impossible." Mind. Available on the author's webpage. $\mathrm{URL}=<\mathrm{http}: / /$ www.jackspencer.org $>$. Accessed on October 13, 2015.

Stalnaker, Robert C. 1968. "A Theory of Conditionals." In Studies in Logical Theory, edited by Nicholas Rescher, 98-112. Oxford: Blackwell.

Vetter, Barbara. 2015. Potentiality: From Dispositions to Modality. Oxford: Oxford University Press.

Williamson, Timothy. 2000. Knowledge and Its Limits. Oxford: Oxford University Press.

-2007. The Philosophy of Philosophy. Oxford: Blackwell.

-2016. "Knowing by Imagining." In Knowledge Through Imagination, edited by Amy Kind and Peter Kung, 113-23. Oxford: Oxford University Press.

-manuscript. "Modal Science." Available on the author's webpage. URL $=<\mathrm{http}: / /$ www.philosophy.ox.ac.uk/members/philosophy_panel/tim_williamson>. Accessed on October 9, 2015.

Yablo, Stephen. 1993. "Is Conceivability a Guide to Possibility?" Philosophy and Phenomenological Research 53: 1-42.

Yli-Vakkuri, Juhani. 2013. "Modal Skepticism and Counterfactual Knowledge." Philosophical Studies 162: 605-23. 